\title{
REGENERASI ALAMI SEMAI Rhizophora apiculata DI KAWASAN INDUSTRI PERMINYAKAN DAN KAWASAN NON INDUSTRI PROVINSI RIAU
}

\author{
Syahrial $^{1,2}$, Yeni Sustriani ${ }^{1}$, Verid Aria Susammesin ${ }^{1}$, Desy \\ Purnamasari Taher ${ }^{1}$, Nur Atikah ${ }^{1}$, Khairul Mukmin Lubis ${ }^{1}$, Ilham Ilahi ${ }^{1}$, \\ Aras Mulyadi ${ }^{3}$, Bintal Amin ${ }^{3}$, Sofyan H Siregar ${ }^{3}$ \\ ${ }^{1}$ Belukap Mangrove Club Jurusan Ilmu Kelautan Universitas Riau \\ ${ }^{2}$ Alumni Departemen IImu dan Teknologi Kelautan, Institut Pertanian \\ Bogor \\ ${ }^{3}$ Jurusan IImu Kelautan Universitas Riau \\ Email: syahrial.bmc@gmail.com
}

Received August 2017, Accepted September 2017

\begin{abstract}
ABSTRAK
Hutan mangrove menyediakan berbagai pelayanan ekologi, namun saat ini sedang mengalami tekanan dari aktivitas manusia misalnya industrialisasi di wilayah pesisir. Kajian regenerasi alami semai populasi Rhizophora apiculata telah dilakukan diantara kawasan industri perminyakan dan kawasan non industri Provinsi Riau. Penelitian ini bertujuan sebagai dasar evaluasi terhadap pengelolaan mangrove di Provinsi Riau kedepannya. Pengambilan sampel mangrove menggunakan transek garis dengan variabel yang diamati adalah kerapatan alami semai $R$. apiculata, karakteristik parameter lingkungan, serta hubungan regenerasi alami semai $R$. apiculata terhadap kualitas perairannya. Hasil penelitian menunjukan bahwa kerapatan regenerasi semai alami $R$. apiculata tertingginya berada di kawasan non industri (Stasiun 4) dan kerapatan semai alami terendahnya berada di kawasan industri perminyakan (Stasiun 1, 2 dan 3). Selain itu, faktor kualitas perairan masih dalam batasan toleransi bagi kehidupan regenerasi semai alami $R$. apiculata dengan suhu perairan tertingginya berada di Stasiun 3, salinitas (Stasiun 4), pH (Stasiun 1), DO (Stasiun 4) dan potensial redoks (Stasiun 1). Selain itu, berdasarkan analisis keterkaitan kualitas perairan terhadap regenerasi semai alami $R$. apiculata mengunakan PCA, pada Stasiun 2, 3 dan 4 dicirikan oleh parameter suhu dan DO. Sementara Stasiun 1 dicirikan oleh parameter potensial redoks dan $\mathrm{pH}$.
\end{abstract}

Kata kunci : regenerasi, semai, Rhizophora apiculata, kawasan industri, Provinsi Riau.

\section{ABSTRACT}

Mangrove forest provided a various of ecological services, but it obtained the anthropogenic activities pressure, such as industrialization on coastal 
area. Analysis of natural seedlings regeneration of Rhizophora apiculata population was conducted between petroleum industry area and nonindustry area in Riau Province. This research aims as evaluation basic on mangrove management in Riau Province for the future. Mangrove samples were taken by using line transect with varriables those are $R$. apiculata natural seedling density, environmental parameter characteristic and relation of $R$. apiculata natural seedling regeneration to water qualities. The results show that the highest $R$. apiculata natural seedling density is in non-industry area (Station 4) and the lowest is in petroleum industry area (Station 1, 2 and 3). Furthemore, water qualities are still in tolerance limit for $R$. apiculata natural regeneration life of seedlings with the highest for temperature (Station 3), salinity (Station 4), $\mathrm{pH}$ (Station 1), DO (Station 4), and ORP (Station 1). On the other hand, base on Principal Component Analysis (PCA), Station 2, 3 and 4 are characterized by temperature and $\mathrm{DO}$, Station 1 is characterized by ORP and $\mathrm{pH}$.

Keywords: regeneration, seedlings, Rhizophora apiculata, industry area, Riau Province.

\section{PENDAHULUAN}

Ekosistem mangrove di Provinsi Riau memiliki peranan ekologi yang besar bagi lingkungan sekitarnya dan tidak jauh berbeda dengan peranan ekosistem mangrove di wilayah lain. Menurut Kaewtubtim et al. (2016) hutan mangrove merupakan hutan yang unik, berfungsi sebagai daerah asuhan bagi fauna akuatik, sebagai habitat penting bagi biota ikan, krustasea, makrofauna dan mikrofauna yang tergabung dalam jaringan makanan. Kemudian Tripathi et al. (2016) menyatakan bahwa mangrove memainkan peran utama dalam siklus biogeokimia dan bertindak sebagai reservoir dalam asimilasi tersier limbah.

Di Provinsi Riau, pada tahun 1929 luas hutan mangrovenya mencapai 182017 ha (van Bodegom, 1929), sedangkan pada tahun 1987 mencapai 470000 ha (Silvius et al. 1987). Kemudian pada tahun 1997, luas hutan mangrove di Provinsi Riau menurun hingga mencapai 234517 ha (Dinas Kehutanan Dati I Riau, 1997) dan pada tahun 2011 menurun kembali hingga 119260 ha (BPS, 2013). Menurut Prianto et al. (2006) kerusakan ekosistem mangrove di Propinsi Riau disebabkan oleh penebangan yang berlebihan untuk pemenuhan kebutuhan kayu arang maupun kebutuhan bahan bangunan, konversi lahan untuk perluasan pemukiman, industri, pelabuhan, lahan budidaya dan pencemaran perairan. Akibat dari kerusakan tersebut, mengakibatkan berkurangnya luasan hutan mangrove dan hilangnya keanekaragaman hayati di beberapa tempat.

Terlepas dari hal di atas, Provinsi Riau juga merupakan salah satu provinsi yang terkenal dengan kawasan industrinya. Hal ini karena letak geografis Provinsi Riau yang berada di jalur transportasi tersibuk di dunia yakni Selat Melaka. Kawasan industri Provinsi Riau yang terkenal adalah Kawasan Industri Dumai (KID) dan Kawasan Industri Bukit Batu (KIBB). KID merupakan kawasan industri Provinsi Riau yang memproduksi minyak 
maupun gas bumi, Crude Palm Oil (CPO) dan Virgin Coconut Oil (VCO), sedangkan KIBB merupakan kawasan industri yang mengolah minyak dan gas bumi dari Kota Dumai. Sementara itu, hutan mangrove di Provinsi Riau tumbuh dan tersebar di sekitar kawasan industri tersebut.

Studi regenerasi mangrove telah banyak dilakukan di berbagai wilayah (misalnya Sillanpaa et al. 2017; Mukhlisi dan Gunawan, 2016; Upadhyay et al. 2015; Ferreira et al. 2015 maupun Sukardjo et al. 2014), tetapi penelitian mengenai regenerasi semai alami khususnya spesies Rhizophora apiculata di sekitar kawasan industri perminyakan dan kawasan non industri masih sangat sedikit dilakukan, sehingga penelitian ini sangat perlu dilakukan dan dapat dijadikan sebagai dasar evaluasi terhadap pengelolaan mangrove di Provinsi Riau kedepannya.

\section{MATERI DAN METODE}

\section{Waktu dan Tempat Penelitian}

Penelitian dilaksanakan pada bulan November hingga Desember 2014 di pesisir pantai Kota Dumai dan Kabupaten Bengkalis (Gambar 1). Stasiun 1 adalah ekosistem mangrove di sekitar KID Lubuk Gaung yang merupakan kawasan industri CPO (Kota Dumai), Stasiun 2 di ekosistem mangrove sekitar KID Bukit Kapur Raksa yang merupakan gabungan kilang minyak Pertamina Refinery Unit II Dumai, Chevron dan industri CPO (Kota Dumai). Sementara Stasiun 3 adalah ekosistem mangrove di sekitar KIBB yang merupakan kilang minyak Pertamina UP II Pakning (Kabupaten Bengkalis) dan Stasiun 4 adalah ekosistem mangrove di Tanjung Medang Rupat Utara yang merupakan kawasan alami mangrove/tidak ada aktivitas industri di sekitarnya (Kabupaten Bengkalis).

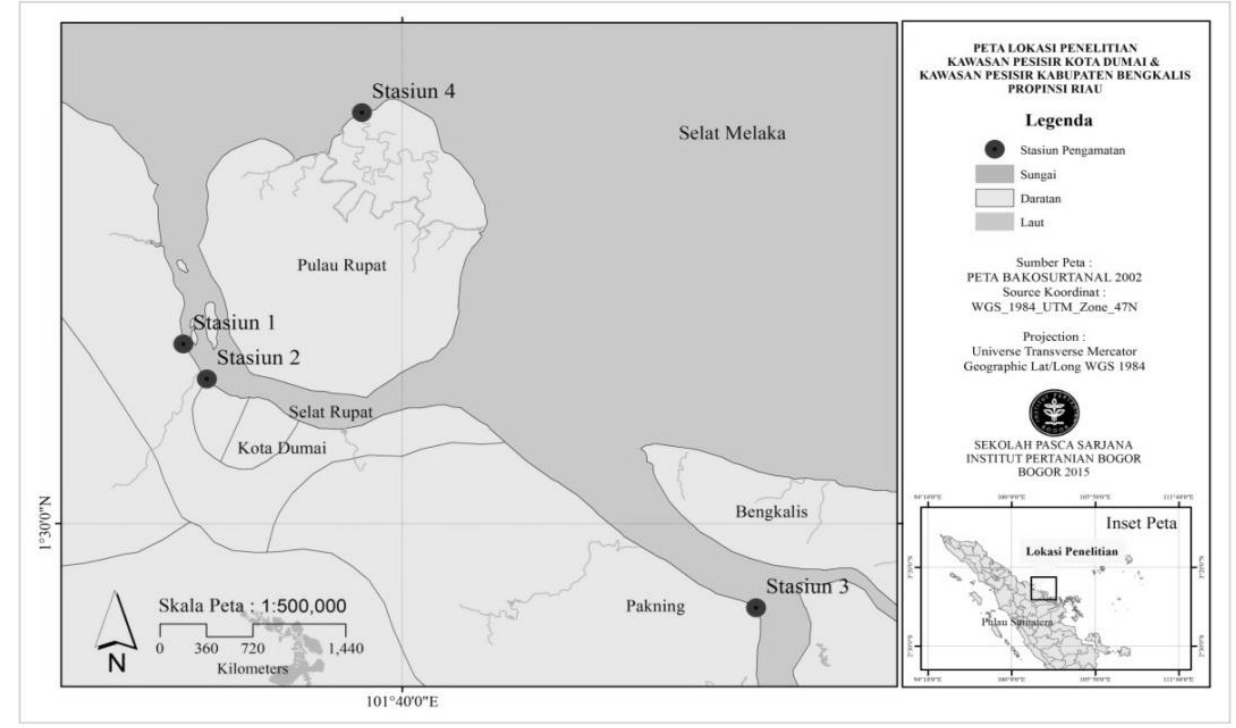

Gambar 1. Peta lokasi pengamatan dan titik pengamatan di ekosistem mangrove sekitar lokasi kawasan industri perminyakan Kota Dumai dan Kabupaten Bengkalis 


\section{Alat dan Bahan Penelitian}

Peralatan yang digunakan selama di lapangan adalah rol meter, buku identifikasi mangrove Noor et al. (2006), data sheet, kamera, GPS Garmin Montana 650, water quality meter (suhu, DO, salinitas, pH) dan ORP meter Lutron 203.

\section{Pengumpulan Data Kualitas Perairan}

Pengukuran kualitas perairan dilakukan dengan cara insitu yakni mengambil contoh air pada masing-masing stasiun pengamatan. Parameter kualitas perairan yang diukur meliputi suhu perairan, $\mathrm{pH}$, salinitas dan oksigen terlarut (Dissolved Oxygen/DO) dengan menggunakan water quality meter, sementara Oksidasi Reduksi Potensial (ORP)/potensial redoks diukur menggunakan ORP Meter Litron 203.

\section{Pengumpulan Data Kondisi Populasi R. apiculata}

Pengukuran populasi $R$. apiculata dilakukan menggunakan transek garis yang ditarik dari titik acuan (tegakan mangrove terluar) dengan arah tegak lurus garis pantai sampai kedaratan. Kemudian dibuat petak contoh kategori pohon dengan ukuran $10 \times 10 \mathrm{~m}^{2}$, kategori anakan $\left(5 \times 5 \mathrm{~m}^{2}\right)$ dan kategori semai $\left(1 \times 1 \mathrm{~m}^{2}\right)$ (Gambar 2) (Bengen, 2004).

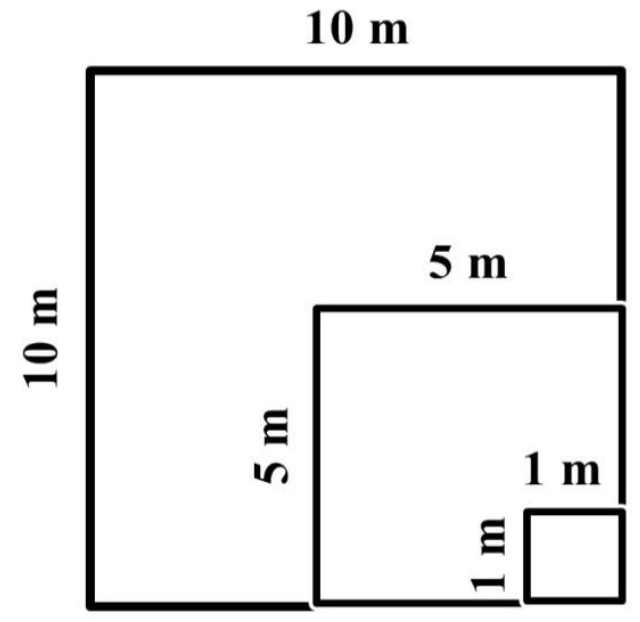

Gambar 2. Petak contoh pengukuran kerapatan regenerasi alami semai populasi $R$. apiculata

\section{Analisis Kerapatan Semai Alami Populasi $R$. apiculata}

Untuk menghitung kerapatan semai populasi $R$. apiculata, digunakan metode penghitungan yang mengacu pada English et al. (1994) dan Bengen (2004). 


\section{Analisis Korelasi Kualitas Perairan dan Regenerasi Alami Semai $\boldsymbol{R}$. apiculata}

Keterkaitan parameter kualitas perairan yang terdiri dari suhu, salinitas, $\mathrm{pH}, \mathrm{DO}$ dan potensial redoks dengan regenerasi alami semai populasi $R$. apiculata digunakan analisis statistik multivariabel yang didasarkan pada analisis komponen utama (Principle Component Analysis/PCA) (Bengen, 2000; Pradhan et al. 2009) menggunakan software XLSTAT 2014.

\section{HASIL DAN PEMBAHASAN}

\section{Kerapatan Semai Populasi $\boldsymbol{R}$. apiculata}

Kerapatan semai alami populasi $R$. apiculata untuk setiap stasiunnya bervariasi, dimana pada Stasiun 1 kerapatannya sebesar $20000.00 \mathrm{ind} / \mathrm{m}^{2}$, sedangkan di Stasiun 2 sebesar $28888.89 \mathrm{ind} / \mathrm{m}^{2}$. Sementara pada Stasiun 3 kerapatan semai populasi $R$. apiculata sebesar $22222.22 \mathrm{ind} / \mathrm{m}^{2}$ dan Stasiun 4 sebesar 36666.67ind $/ \mathrm{m}^{2}$ (Gambar 3).

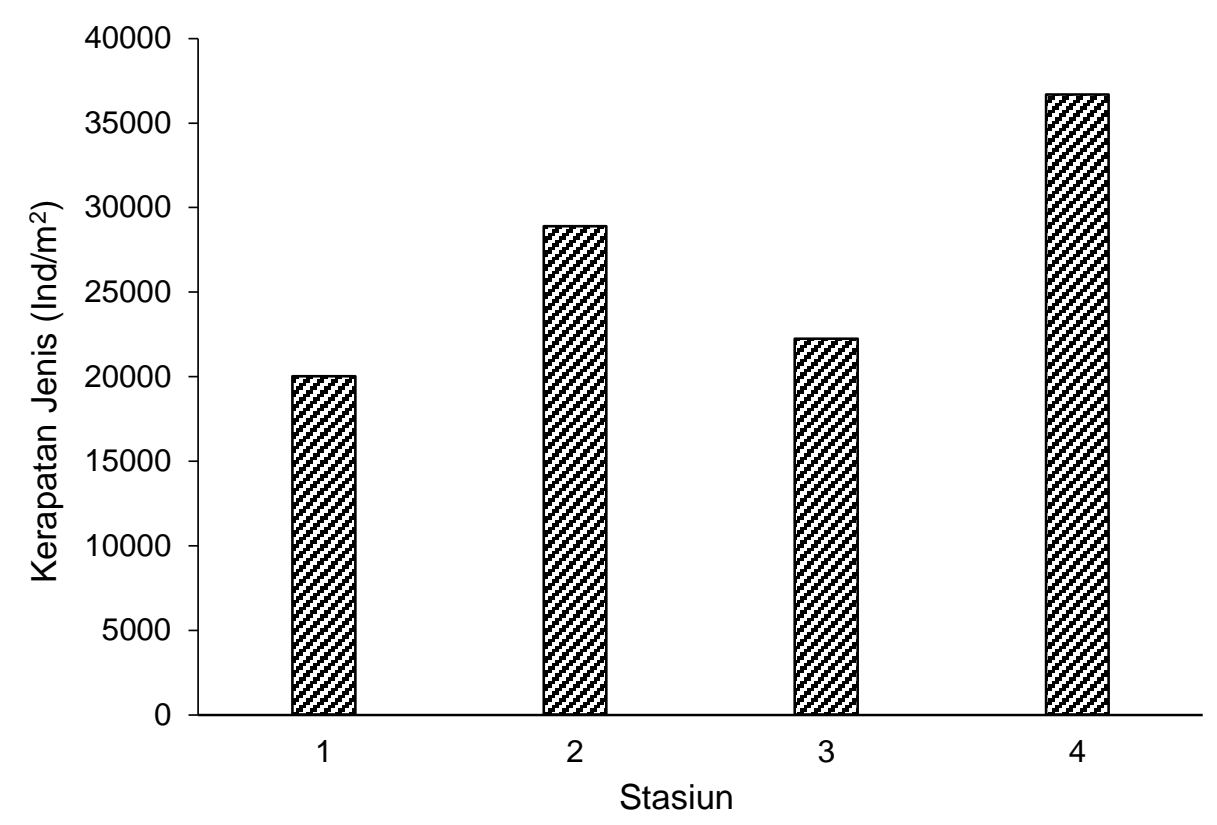

Gambar 3. Kerapatan semai alami populasi $R$. apiculata di kawasan industri perminyakan dan kawasan non industri Provinsi Riau

Tingginya kerapatan semai alami populasi $R$. apiculata di Stasiun 4 disebabkan oleh kawasan mangrovenya masih alami, sehingga masih banyak ditemukan pohon-pohon induknya. Hal ini menandakan bahwa aktivitas penebangan pohon di Stasiun 4 masih sangat rendah dan menunjukan regenerasi yang masih baik. Menurut Mukhlisi dan Gunawan (2016) regenerasi semai pada hutan mangrove merupakan salah satu 
bagian penting dalam proses suksesi sekunder, kemudian tumbuhnya jenis-jenis semai alami mangrove memiliki hubungan erat dengan ketersediaan pohon induknya.

\section{Karakteristik Parameter Lingkungan Populasi R. apiculata}

Kualitas air sangat penting untuk kelangsungan hidup dan kesejahteraan sumberdaya hayati, terutama di daerah pesisir dan muara (Nobi et al. 2010). Hasil pengukuran kualitas perairan di lapangan memperlihatkan bahwa rata-rata suhu perairan di Stasiun 1 adalah $28.30^{\circ} \mathrm{C}$, Stasiun $2\left(30.00^{\circ} \mathrm{C}\right)$, Stasiun $3\left(30.70^{\circ} \mathrm{C}\right)$ dan Stasiun 4 $\left(30.30^{\circ} \mathrm{C}\right)$ (Tabel 1). Bervariasinya suhu perairan di lokasi penelitian, diduga karena pengaruh dari batimetri perairan. Menurut Xie et al. (2002) suhu suatu perairan dapat dipengaruhi oleh kondisi batimetri. Kemudian Kusmana (2005) menyatakan bahwa suhu yang baik untuk tumbuhan mangrove tidak kurang dari $20^{\circ} \mathrm{C}$.

Tabel 1. Karakteristik Kondisi Lingkungan di Lokasi Penelitian

\begin{tabular}{cccccc}
\hline Stasiun & $\begin{array}{c}\text { Suhu } \\
\left({ }^{\circ} \mathrm{C}\right)\end{array}$ & $\begin{array}{c}\text { Salinitas } \\
(\%)\end{array}$ & $\mathrm{pH}$ & $\begin{array}{c}\mathrm{DO} \\
(\mathrm{ppm})\end{array}$ & $\begin{array}{c}\text { Potensial } \\
\text { Redoks }(\mathrm{mV})\end{array}$ \\
\hline 1 & 28.30 & 30.00 & 7.90 & 5.40 & 124.00 \\
2 & 30.00 & 30.30 & 7.30 & 5.20 & 105.00 \\
3 & 30.70 & 27.30 & 7.50 & 5.50 & 102.00 \\
4 & 30.30 & 31.30 & 7.30 & 6.40 & 104.00 \\
\hline
\end{tabular}

Tabel 1 juga memperlihatkan bahwa salinitas di Stasiun 1 mencapai 30.00\%, Stasiun 2 (30.30\%o), Stasiun $3(27.30 \%$ ) dan Stasiun 4 (31.30\%o). Tingginya salinitas di Stasiun 4 karena berdekatan dengan Selat Melaka (perairan terbuka) yang membentuk jalur pelayaran terusan Samudera Hindia dan Samudera Pasifik. Menurut Thia-Eng (2000) salinitas permukaan di perairan terbuka berkisar antara $30.80-31.83 \%$. Sementara, rendahnya salinitas di Stasiun 3 disebabkan karena disekitar lokasi penelitian terdapat aliran sungai yang bermuara ke laut Bengkalis. Menurut Hamzah dan Setiawan (2010) rendahnya salinitas diduga karena berdekatan dengan sumber air tawar seperti sungai. Kemudian, nilai pH perairan di Stasiun 1 sebesar 7.90, Stasiun 2 (7.30), Stasiun 3 (7.50) dan Stasiun 4 (7.30) (Tabel 1). Rendahnya nilai pH perairan di Stasiun 2 dan 4 diduga karena adanya proses reduksi dan oksidasi serta adanya proses dekomposisi serasah mangrove oleh pengurai. Hamzah dan Setiawan (2010) menyatakan bahwa faktor yang mempengaruhi rendahnya nilai $\mathrm{pH}$ adalah proses reaksi reduksi dan oksidasi yang terjadi. Kemudian Gopinath et al. (2010) menyatakan bahwa penurunan $\mathrm{pH}$ juga dapat disebabkan oleh asam yang dilepaskan pada saat akumulasi dekomposisi bahan organik.

Selain itu, Tabel 1 juga menunjukan bahwa nilai DO di Stasiun 4 merupakan nilai yang tertinggi bila dibandingkan dengan stasiun lainnya (6.40 ppm). Hal ini diduga karena tingginya proses fotosintesis di perairan 
tersebut pada saat pengukuran. Hadiputra dan Damayanti (2013) menyatakan bahwa sumber utama DO di perairan berasal dari hasil proses fotosintesis tumbuhan. Sementara, nilai potensial redoks di Stasiun 3 merupakan kadar DO terendah bila dibandingkan dengan stasiun yang lain. Menurut Rahman et al. (2013) tingginya nilai potensial redoks sangat berpengaruh terhadap curah hujan dan pasang surut yang signifikan.

\section{Hubungan Regenerasi Alami Semai Populasi $R$. apiculata dan Kualitas Perairan}

Kondisi fisikokimia perairan akan berpengaruh terhadap fisiologi serta pertumbuhan mangrove (Hamzah dan Pancawati, 2013). Hasil analisis PCA memperlihatkan bahwa terdapat dua (2) kelompok parameter yang dominan dan berkorelasi positif dengan regenerasi alami semai populasi $R$. apiculata pada kawasan industri perminyakan dan kawasan non industri di Provinsi Riau. Kelompok pertama dicirikan oleh parameter suhu dan DO (Stasiun 2, 3 dan 4), sedangkan kelompok kedua dicirikan oleh parameter potensial redoks dan $\mathrm{pH}$ (Stasiun 1) (Gambar 4). Hal ini mengambarkan bahwa hampir seluruh parameter kualitas perairan memiliki korelasi positif/kuat terhadap keberadaan regenerasi semai alami populasi $R$. apiculata di masing-masing stasiun, kecuali parameter salinitas karena memiliki korelasi yang rendah. Rendahnya korelasi parameter salinitas terhadap regenerasi semai alami populasi $R$. apiculata ditandai dengan arah panah yang tegak lurus dan sudut yang terbentuk sangat lebar, sedangkan tingginya korelasi parameter DO dan suhu maupun potensial redoks dan $\mathrm{pH}$ ditandai dengan arah panah yang sama. Menurut Leps dan Smilaeur (2003) variabel dengan arah panah yang sama, memiliki arti bahwa antar variabel berkorelasi positif, sedangkan arah panah yang berlawanan memiliki arti berkorelasi negatif, kemudian arah panah yang tegak lurus artinya tidak memiliki korelasi, serta nilai sudut antar dua panah yang terbentuk akan menggambarkan kekuatan korelasi bagi kedua variabel tersebut (makin sempit sudut yang terbentuk antar dua variabel, maka makin positif/tinggi korelasinya dan begitu sebaliknya).

Berdasarkan Keputusan Menteri Negara Lingkungan Hidup Nomor 51 Tahun 2004 Tentang Baku Mutu Air Laut untuk Biota Laut, secara keseluruhan kisaran parameter kualitas perairan yang diukur masih dalam batasan toleransi bagi kehidupan regenerasi alami semai $R$. apiculata di antara kawasan industri perminyakan dan kawasan non industri Provinsi Riau. 


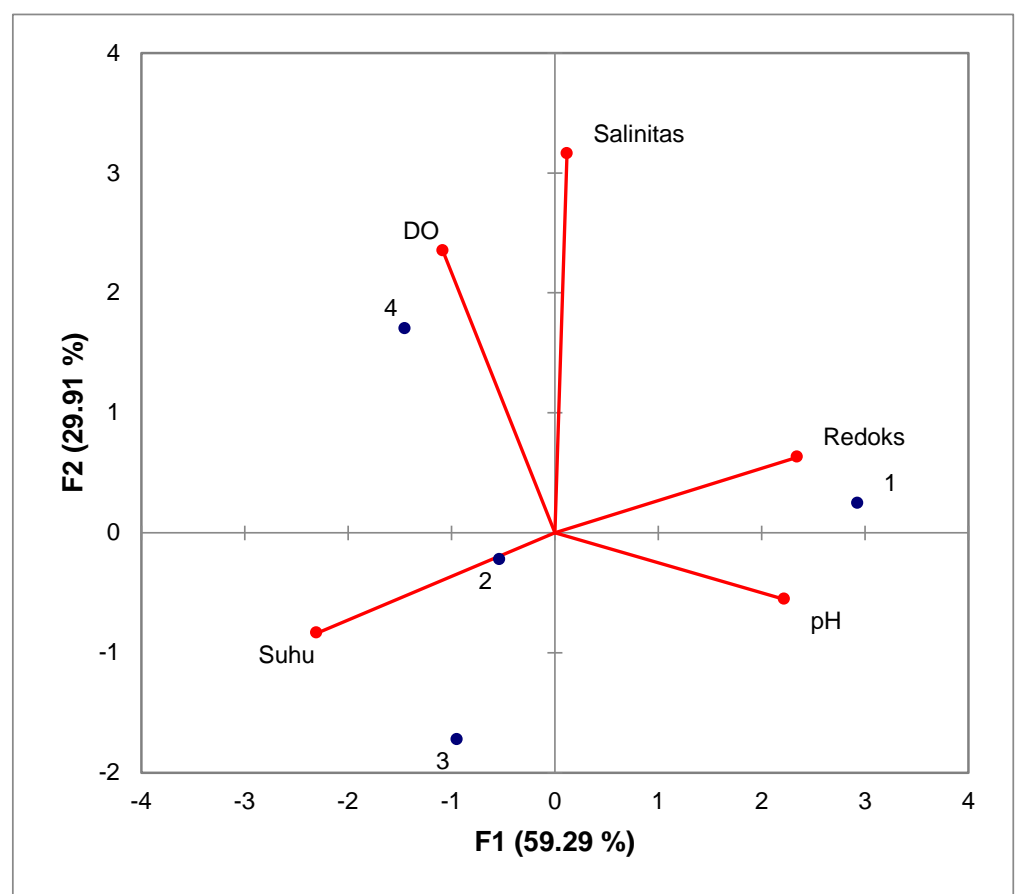

Gambar 4. Diagram keterkaitan parameter kualitas perairan dengan regenerasi alami semai $R$. apiculata

\section{KESIMPULAN}

Kerapatan regenerasi alami semai $R$. apiculata antara kawasan industri perminyakan dan kawasan non industri di Provinsi Riau bervariasi setiap stasiunnya. Kerapatan tertinggi terdapat pada Stasiun 4 (kawasan non industri) dan terendah pada Stasiun 1 (kawasan industri minyak $\mathrm{CPO}$ ). Kemudian secara keseluruhan, kisaran parameter kualitas perairan masih dalam batasan toleransi bagi kehidupan mangrove di antara kedua kawasan, dimana pada Stasiun 1 mempunyai korelatif yang kuat terhadap parameter potensial redoks dan $\mathrm{pH}$, sedangkan pada Stasiun 2, 3 dan 4 mempunyai hubungan yang kuat terhadap parameter suhu dan DO.

\section{DAFTAR PUSTAKA}

Bengen, D.G. 2000. Teknik Pengambilan Contoh dan Analisis Data Biofisik Sumberdaya Pesisir. PKSPL-IPB. Bogor (ID): IPB Pr.

Bengen, D.G. 2004. Pedoman Teknis Pengenalan dan Pengelolaan Ekosistem Mangrove. Bogor (ID): Pusat Kajian Sumberdaya Pesisir dan Lautan, IPB.

[BPS] Badan Pusat Statistik Provinsi Riau. 2013. Riau Dalam Angka 2013. Pekanbaru, Indonesia.

Dinas Kehutanan Dati I Riau.1997. Laporan Tahunan Dinas Kehutanan Daerah Tingkat I Propinsi Riau. Pekanbaru.

English, S., Wilkinson C., Baker V. 1994. Survey Manual For Tropical Marine Resources. ASEAN-Australia Marine Science Project: 
Living Coastal Resources, Australian Institute of Marine Science. Townsvile (AUS).

Ferreira, A.C., Ganade G, de Attayde, J.L. 2015. Restoration versus natural regeneration in a neotropical mangrove: Effects on plant biomass and crab communities. Ocean Coast Manag. 110:38-45.

Gopinath, A., Nair, S.M., Kumar, N.C., Jayalaksmi, K.V., Pamalal, D. 2010. A baseline study of trace metals in a coral reef sedimentary environment, Lakshadweep Archipelago. Environ Earth Sci. 59:1245-1266.

Hadiputra, M.A., Damayanti, A. 2013. Kajian potensi makrozoobentos sebagai bioindikator pencemaran logam berat tembaga $(\mathrm{Cu}) \mathrm{di}$ kawasan ekosistem mangrove Wonorejo Pantai Timur Surabaya. Dalam: Prosiding Seminar Nasional Manajemen Teknologi XVIII. 27 Juli 2013. Surabaya, Indonesia.

Hamzah, F., Pancawati, Y. Fitoremidiasi logam berat dengan menggunakan mangrove. Ilmu Kel. 18(4):203-212.

Hamzah, F., Setiawan, A. 2010. Akumulasi logam berat $\mathrm{Pb}, \mathrm{Cu}$, dan $\mathrm{Zn}$ di hutan mangrove Muara Angke, Jakarta Utara. ITKT. 2(2):41-52.

Kaewtubtim, P., Meeinkuirt, W., Seepom, S., Pichtel, J. 2016. Heavy metal phytoremediation potential of plant species in a mangrove ecosystem in Pattani Bay, Thailand. AEER. 14(1): 367-382

[KLH] Kementerian Lingkungan Hidup Republik Indonesia. 2004. Baku Mutu Air Laut untuk Biota Laut. Dalam: Keputusan Menteri Negara Lingkungan Hidup No. 51 Tahun 2004 Tentang Baku Mutu Air Laut. KLH, Jakarta.

Kusmana, C. 2005. Rencana rehabilitasi hutan mangrove dan hutan pantai pasca tsunami di NAD dan Nias. Dalam: Lokakarya Hutan Mangrove Pasca Tsunami. April 2005. Medan, Indonesia.

Leps, J., Smilauer, P. 2003. Multivariate Analysis of Ecological Data Using CANOCO. United Kingdom: Cambridge University Press. Inggris.

Mukhlisi, Gunawan, W. 2016. Regenerasi alami semai mangrove di areal terdegradasi Taman Nasional Kutai. Penel Kehut Wall. 5(2):113122.

Nobi, E.P., Dilipan, E., Thangaradjou, T., Silvakumar, K., Kannan, L. 2010. Geochemical and geo-statistical assessment of heavy metal concentration in the sediments of different coastal ecosystems of Andaman Islands, India. Est Coast Shelf Sci. 87:253-264.

Noor, Y.R., Khazali, M., Suryadiputra, I.N.N. 2006. Panduan Pengenalan Mangrove di Indonesia. Bogor (ID):PHKA/WI-IP.

Pradhan, U.K., Shirodkar, P.V., Sahu, B.K. 2009. Physico-chemical characteristics of the coastal water off Devi estuary, Orissa and evaluation of its seasonal changes using chemometric techniques. Cur Sci: 96(9):1203-1209.

Prianto, E., Jhonnerie, R., Firdaus, R., Hidayat, T., Miswadi. 2006. Keanekaragaman hayati dan struktur ekologi mangrove dewasa di kawasan pesisir Kota Dumai Provinsi Riau. Biodiversitas. 7(4):327-332. 
Rahman, M.M., Rahman, M.T., Rahaman, M.S., Rahman, F., Ahmad, J.U., Shakera, B., Halim, M.A. 2013. Water quality of the world's largest mangrove forest. Can Chem Tran. 1(2):141-156.

Sillanpaa, M., Vantenllingen, J., Friess, D.A. 2017. Vegetation regeneration in a sustainably harvested mangrove forest in West Papua, Indonesia. For Ecol Manag. 390:137-146.

Silvius, M.J., Steeman, A.P.J.M., Berczy, E.T., Djuharsa, E., Taufik, A. 1987. The Indonesian Wetland Inventory. A Preliminary Compilation of Existing Information on Wetlands of Indonesia. PHPA, AWB/INTERWADER, EDWIN. Bogor, Indonesia.

Sukardjo, S., Alongi, D.M., Ulumuddin, Y.I. 2014. Mangrove community structure and regeneration potential on a rapidly expanding, river delta in Java. Trees. 28(4):1105-1113.

Thia-Eng, C., Gorre, I.R.L., Ross, S.A., Bernad, S.R., Gervacio, B., Ebarvia, M.C. 2000. The Malacca Straits. Mar Poll Bull. 41(16):160-178.

Tripathi, R., Shukla, A.K., Shahid, M., Nayak, D., Puree, C., Mohanty, S., Raja, R., Lal, B., Gautam, P., Bhattacharyya, P., Panda, B.B., Kumar, A., Jambhulkar, N.N., Nayak, A.K. 2016. Soil quality in mangrove ecosystem deteriorates due to rice cultivation. Ecol Engin. 90:163-169.

Upadhyay, R., Joshi, N., Sampat, A.C., Verma, A.K,, Patel, A., Singh, V., Kathota, J., Kalubarme, M.H. 2015. Mangrove restoration and regeneration monitoring in Gulf of Kachchh, Gujarat State, India, using remote sensing and geo-informatics. Internat Jour Geosc. 6:299-310.

van Bodegom, A.H. 1929. De vloedbosschen in het gewest Riouw en onderhoorigheden. Tectona. 22:1302-1332.

Xie, S., Hafner, J., Tanimoto, Y., Liu, W.T., Tokinaga, Xu, H. 2002. Bathymetric effect on the winter sea surface temperature and climate of the Yellow and East China Seas. Geop ResLett. 29(24):2228. 